\title{
UK consumer perceptions of starchy foods
}

\author{
Karin Stubenitsky* and David J. Mela† \\ Consumer Sciences Department, Institute of Food Research, Reading RG6 6BZ, UK
}

(Received 5 May 1999 - Revised 17 August 1999 - Accepted 23 August 1999)

\begin{abstract}
To gain an understanding of UK consumer attitudes and beliefs regarding starchy foods and their dietary role, a questionnaire based on the theory of planned behaviour was developed and sent out to a UK consumer sample ( $n$ 800). The content focused on attitudes and beliefs towards starchy foods, perceived barriers towards increasing their intake (e.g. cost, habit, social influences), perceptions of personal and recommended starchy food intake, intention to increase starchy food intakes in the future and socio-demographic information. Responses ( $n$ 414) indicated that consumers have highly divergent attitudes and beliefs regarding starchy foods. These foods are seen as nutritious and good for one's health, but also as high in energy and not helping to control weight, and the overall intention to increase starchy food intake was extremely low. Possible barriers towards increasing starchy food intake were the perceptions that personal starchy food intakes were already high, beliefs that starchy food intakes should be reduced to achieve a healthier diet, and the view that personal starchy food intakes did not need to be changed any further, because (depending on attitude) individual's intakes had already been increased or reduced. The model including attitude and subjective norm had the best fit for predicting reported intention to increase starchy food consumption, with attitude being the strongest contributor. Addition of the factor 'family's liking of starchy foods' significantly improved the model. For reported starch intake, the model including attitude had the best fit, and addition of other factors did not improve the model. These findings indicate that health promotion strategies aimed at increasing complex carbohydrate intakes should take these perceptions into consideration; however, further work is required to examine how these potential barriers can best be addressed in practice.
\end{abstract}

Starchy foods: Carbohydrate: Consumer attitudes

An increase in the proportion of dietary energy from carbohydrates forms part of current public health nutrition guidance in many Western nations (Cannon, 1992), largely to help attain a lower percentage of energy from fat in the diet. In the UK, carbohydrate intakes have remained stable for several years at approximately $45 \%$ of total energy intake (Ministry of Agriculture, Fisheries and Food, 1992, 1996), despite the recommendation to increase consumption to at least $50 \%$ of energy (Department of Health, 1994). The recommendations in the UK and elsewhere commonly specify that this dietary goal should be achieved by increasing intakes of starchy foods high in complex carbohydrate, such as potatoes, breads, pasta and rice (Cannon, 1992).

Although there have been several studies which have focused on attitudes, beliefs and barriers with regard to specific fat reduction strategies, there is little similar work addressing these issues in relation to increasing consumption of starchy foods. Our research on barriers towards making general dietary changes, focusing on reducing fat intake (Lloyd et al. 1993, 1995; Paisley, 1994; Paisley et al. $1995 a, b)$, indicated that UK consumers generally do not view increasing the proportion of bread, rice, pasta and potatoes in the diet as a desirable dietary change. Goode et al. (1995) reported that only about $50 \%$ of UK consumers recognized that current health guidelines recommend an increase in the consumption of these foods, despite over $90 \%$ correctly identifying general guidance regarding other foods and nutrients (e.g. salt, sugar, fruit and vegetables, etc.). Buttriss (1997) reported similar results. Shepherd et al. (1997) reported that only $20 \%$ of their UK respondents agreed that 'people in Britain should eat more starchy carbohydrate'. Moreover, starchy foods are generally viewed as fattening and 'boring but filling' (Stephen et al. 1995). There is clearly a need to address consumer perceptions of starchy foods and their role in the diet, and a broader understanding of consumer views could therefore be of

\footnotetext{
Abbreviations: HRS, high reported starch intake; LRS, low reported starch intake; TPB, theory of planned behaviour.

* Corresponding author: Ms Karin Stubenitsky, present address Consumer and Applications Science, New Zealand Dairy Research Institute, Palmerston North, New Zealand, fax +64 6356 1476, email karin.stubenitsky@nzdri.org.nz

$\dagger$ Present address: Unilever Research Vlaardingen, Vlaardingen, The Netherlands.
} 
major importance in targeting the promotion of this dietary change.

The theory of planned behaviour (TPB) (Ajzen \& Fishbein, 1980; Ajzen, 1985) allows the development of a structured method which can be used to access individual beliefs and attitudes and their relationships with food choice (Saunders \& Rahilly, 1990; Towler \& Shepherd, 1991; Sparks et al. 1992; Brug et al. 1994; Paisley, 1994). In the TPB model, behaviour is primarily predicted by someone's intention to perform that behaviour, which in turn is predicted by individual attitudes (favourable or unfavourable) towards the behaviour, other people's influences towards performing the behaviour (subjective norm) and the control people feel they have over the behaviour (perceived behavioural control) (Fig. 1).

Attitudes are predicted as the result of the consequences people expect from the behaviour (beliefs) and the way people value those expected consequences (the importance of the belief). Attitudes can be quantitatively determined as the sum of measures of a set of relevant beliefs (e.g. the extent to which eating a given food is believed to reduce heart disease risk) weighted by the corresponding evaluation of these beliefs (e.g. the perceived importance of eating foods which reduce heart disease risk). Another more direct way of measuring attitude is by using the mean of (a selection of) five separate attitude scales: 'My attitude towards $\mathrm{x}$ is ...' on the following scales 'harmful - beneficial', 'unpleasant - pleasant', 'foolish - wise', 'unenjoyable - enjoyable' and 'bad - good' (Ajzen \& Fishbein, 1980). The mean score on these scales gives a direct attitude measurement which is used in the overall TPB model to predict the intention of a certain behaviour, whereas the summed product of beliefs and outcome evaluations gives a deeper understanding of what factors (beliefs) influence a particular attitude (Ajzen $\&$ Fishbein, 1980). Beliefs and outcome evaluations regarding food cost, availability, convenience of preparation and cooking, effect on health, family's liking of the foods etc., are important in determining food choice, and negative aspects concerning any of these variables can be barriers to desirable nutrition practices.

The present study was an initial evaluation of UK consumer attitudes and beliefs towards starchy foods, and used the TPB model as a basis to investigate barriers towards increasing intakes of starchy foods high in complex carbohydrate.

\section{Methods \\ Survey methodology}

The questionnaire was sent to a convenience sample of 800 individuals in the Reading area in November 1995, using a consumer database from a commercial marketing organization. To help increase the response rate, each questionnaire included a pen and postage-free return envelope, and recipients were informed that $50 \mathrm{p}$ was donated to a registered charity for each completed and returned questionnaire. The actual donation was made after receiving all the completed questionnaires. This last incentive was based on the findings of Dickinson \& Faria (1995), who concluded that contributions to a charitable cause increase the response rate in postal surveys. Ethical approval was given by the Institute of Food Research Human Research Ethics Committee.

\section{Questionnaire design}

The questionnaire booklet began with a brief introduction, followed by questions which were put in random order, and referred to four sections assessing: (1) frequency of eating and preference for selected starchy foods, (2) components of the TPB (Ajzen \& Fishbein, 1980; Ajzen, 1985), (3) questions relating to barriers towards increasing starchy food intake, and (4) socio-demographic details of respondents. Details of each of these are given later. All questions were phrased so that they referred to changing the proportion of starchy foods, rather than simply adding or removing them from the diet, and all responses were given on 7-point category scales. Except as indicated, responses were scored from 1 to 7 , and all were converted so that higher values corresponded to a more positive attitude towards increasing the proportion of starchy foods. A copy of the full questionnaire can be obtained from the corresponding author.

Introduction. The introduction provided some general instructions for consumers to help in completing the questionnaire, and specified a list of examples of the starchy foods which were the focus of the questions. Related research from our laboratory (Monteleone et al. 1997, 1998) has shown that consumers identify different starchy food items as clearly possessing different qualities and nutritional attributes; thus, questions on 'starchy foods' as a generic, unspecified category could lead to inconsistent and ambiguous responses, because the term could be applied to a

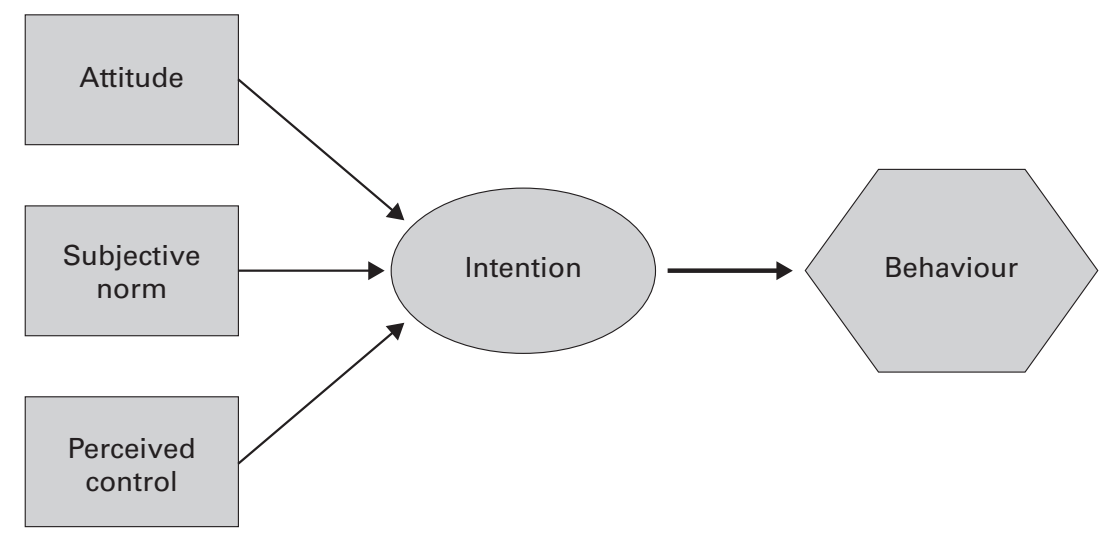

Fig. 1. Theory of planned behaviour according to Ajzen \& Fishbein (1980) and Ajzen (1985). 
widely varied range of food items. The list excluded versions of starchy foods which contain a high proportion of fat or sugars, such as roast or fried potatoes (chips), crisps, biscuits, cakes and pastries, and others which could not directly be recognized as starchy foods, such as other vegetables and vegetable dishes.

(1) Frequency of eating and preference for selected starchy foods. This part asked respondents to list the number of portions they ate from a selected range of starchy food groups (breads, cereals, rice, pasta and potatoes) per day, week, month or rarely/never. The frequency of eating that number of portions per day was used to provide a rough estimation of reported starch intake of the starchy food. From the frequency question, the total portions per day of each starchy food group were calculated. The average size of each portion of a specific starchy food group (Ministry of Agriculture, Fisheries and Food, 1993) was then put into the database, together with the number of portions of that group eaten per day, using food composition data from Paul \& Southgate (1978). On the basis of this, the spreadsheet database calculated total weight $(\mathrm{g})$ of starch consumed daily. It should be noted, however, that due to the nature of the frequency question, only a rough estimation of total starch intake could be made.

(2) Components of the theory of planned behaviour. Subjective norm, perceived control and intention to increase starchy food intake were each assessed with one single question according to the TPB of Ajzen (1985) (Fig. 2). Attitude was assessed by (a) the mean of two separate (direct) attitude questions, and (b) indirectly by using the belief $\times$ outcome evaluation items (Fig. 2). The direct attitude questions were two questions randomly chosen out of five commonly used attitude questions: 'harmful beneficial', 'pleasant - unpleasant', 'foolish - wise', good - bad' and 'enjoyable - unenjoyable' (Ajzen \& Fishbein, 1980; Ajzen, 1985). The mean score of the two direct attitude questions was used as the attitude measurement in the TPB model, whereas the belief $\times$ outcome evaluation items were used to give a deeper understanding of the factors (beliefs) that influence attitude. The salient beliefs towards starchy foods were derived from past studies and pilot interviews with fifteen members of the public from the Reading area, who did not take part in the main survey. From those interviews the most frequently expressed beliefs were included in the questionnaire. Corresponding outcome evaluation statements were also assessed.

(3) Questions relating to barriers towards increasing starchy food intake. Further questions assessed possible barriers towards increasing starchy food intake. These were: (a) perceived personal starchy food intake: 'Do you believe that the proportion of starchy foods in your diet is ...' from 'extremely low' to 'extremely high', (b) recognition of current dietary guidelines towards starchy foods: 'In order to make your diet more healthy, to what extent do you believe you should make a change in the proportion of starchy foods you have in your diet?' from 'reduce greatly' to 'increase greatly', (c) stage of change in relation to starchy food intake (according to the models of Glanz et al. (1994) and Prochaska (1992)), (d) specific barriers towards increasing starchy food intake (i.e. effects on food cost, availability, convenience of preparation, health, habit and family's liking of starchy foods) e.g. 'I would increase the proportion of starchy foods in my diet if cost/family's liking of starchy foods was not an issue' from 'strongly disagree' to 'strongly agree'. Cost and family's liking of starchy foods were viewed as strong barriers towards dietary change by Paisley et al. $(1995 a, b)$, therefore these factors were selected as additional factors used in the regression analyses trying to improve the predicting intention to increase starch intake and reported starch intake. All questions were assessed by one single question using a 7-point scale.

(4) Socio-demographic details of respondents. Additional questions elicited the respondent's age, sex, height and weight, current or former occupation of the main earner in the household, and other socio-demographic characteristics. On the basis of occupation, respondents were classified by social-class groups (Office of Population Censuses and Surveys, 1991).

\section{Data analyses}

The analysis of the TPB model was carried out according to the method of Ajzen \& Fishbein (1980). Each of the fourteen belief items was multiplied by the corresponding evaluation outcome and the products summed for all belief $x$ outcome evaluation items.

The two dependent variables examined were (1) intention to increase starchy food intake, and (2) reported starch intake. (Forward) stepwise multiple regression was used to generate the best fitting model predicting the dependent variables 'intention to increase starchy food intake' and 'reported starch intake'. The first step was to calculate the contribution of each of the three components of the TPB model (attitude, subjective norm and perceived control) to the best fitting basic model. The second step was to include additional factors such as perceived starchy food intake, stage of change, habit, cost and family's liking of starchy foods, to the first stepwise multiple regression analyses, in order to assess the improvement to the overall prediction, and contribution of each of those factors to the best fitting model.

The independent variables were assessed by labelled 7point category scales. It is common practice to treat these discrete scales as continuous variables with interval-level properties, as suggested in the literature (e.g. Meiselman, 1994), supporting the validity of the numerical values associated with such scales. In addition, our sample size was large, supporting our confidence in not violating the assumption of normality. Therefore differences between groups of respondents were assessed with $t$ tests for continuous data, and using $\chi^{2}$ for categorical data. Unless indicated otherwise, all data are expressed using the mean and standard deviation. All analyses were carried out using Statistical Package for the Social Sciences statistical analysis software (v.6.1 for Windows; SPSS Inc, Chicago, IL, USA).

\section{Results \\ Respondents}

A total of 414 consumers returned the questionnaire, a response rate of $51.8 \%$. The actual respondent sample was 
INTENTION

'How likely is it that you will increase the proportion of starchy foods you have in your diet within the next month?'

$\begin{array}{lllllll}\text { extremely } & \text { quite } & \text { slightly } & \text { neither } & \text { slightly } & \text { quite } & \text { extremely } \\ \text { unlikely } & \text { unlikely } & \text { unlikely } & & \text { likely } & \text { likely } & \text { likely } \\ \square & \square & \square & \square & \square & \square & \square\end{array}$

PERCEIVED CONTROL

'How much control do you personally have over the proportion of starchy foods you have in your diet?'

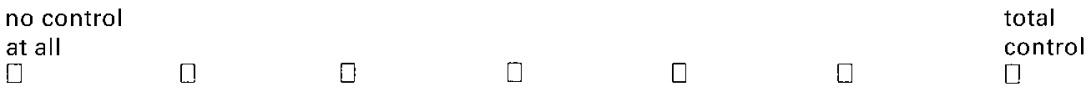

\section{SUBJECTIVE NORM}

How much do you agree or disagree with the following statement? 'People who are important to me think I should increase the proportion of starchy foods I have in my diet'.

$\begin{array}{lllllll}\text { strongly } & \text { quite } & \text { slightly } & \text { neither } & \text { slightly } & \text { quite } & \text { strongly } \\ \text { disagree } & \text { disagree } & \text { disagree } & & \text { agree } & \text { agree } & \text { agree } \\ \square & \square & \square & \square & \square & \square & \square\end{array}$

\section{ATTITUDE}

(a) mean of the scores on the following two questions:

'Do you believe it would be harmful or beneficial for you to increase the proportion of starchy foods you have in your diet?'

$\begin{array}{lllllll}\text { extremely } & \text { quite } & \text { slightly } & \text { neither } & \text { slightly } & \text { quite } & \text { extremely } \\ \text { harmful } & \text { harmful } & \text { harmful } & & \text { beneficial } & \text { beneficial } & \text { beneficial } \\ \square & \square & \square & \square & \square & \square & \square\end{array}$

'Do you believe it would be unpleasant or pleasant for you to increase the proportion of starchy foods you have in your diet?'

$\begin{array}{lllllll}\text { extremely } & \text { quite } & \text { slightly } & \text { neither } & \text { slightly } & \text { quite } & \text { extremely } \\ \text { unpleasant } & \text { unpleasant } & \text { unpleasant } & & \text { pleasant } & \text { pleasant } & \text { pleasant } \\ \square & \square & \square & \square & \square & \square & \square\end{array}$

(b) belief $\mathrm{x}$ outcome evaluation items

Beliefs: 'Having a proportion of starchy foods in my diet means having foods which...' on a 7-point scale from 'strongly disagree/quite disagree/slightly disagree/neither/slightly agree/ quite agree/strongly agree'.

Outcome evaluations: 'For me, having foods in my diet which...' on a 7-point scale from 'extremely unimportant/quite unimportant/slightly unimportant/neither/slightly important/ quite important/extremely important'.

- easily fit into my daily meals

- are good for my health

- help to control my weight

- are filling

- are easy to prepare and cook

- are easy to digest

- are quick to prepare and cook

- are tasty

- are nutritious

- are interesting

- are high in energy

- are easy to store

Fig. 2. Components of the theory of planned behaviour (Ajzen, 1985). 
Table 1. Contribution of the components attitude, subjective norm and perceived control to the overall predictiveness of the theory of planned behaviour model, with either intention to increase starchy food intake or reported starch intake as the dependent variable

\begin{tabular}{|c|c|c|c|c|c|c|}
\hline Step & Variables in model & Adjusted $R^{2}$ & $P$ & $\beta$ & $t$ & $P$ \\
\hline \multicolumn{7}{|c|}{ Intention to increase starchy food intake } \\
\hline 1 & + attitude & $0 \cdot 19$ & $<0.001$ & 0.43 & $9 \cdot 74$ & $<0.001$ \\
\hline 2 (final) & $\begin{array}{l}\text { + attitude } \\
\text { + subjective norm }\end{array}$ & 0.21 & $<0.001$ & $\begin{array}{l}0.38 \\
0.15\end{array}$ & $\begin{array}{l}8 \cdot 30 \\
3 \cdot 12\end{array}$ & $\begin{array}{l}<0.001 \\
<0.001\end{array}$ \\
\hline \multicolumn{7}{|c|}{ Reported starch intake } \\
\hline 1 (final) & + attitude & 0.01 & 0.02 & $0 \cdot 12$ & $2 \cdot 31$ & 0.023 \\
\hline
\end{tabular}

clearly skewed toward higher income and social classes than the average for the UK population, and included a disproportionately high number of females. However, there were few significant differences found in attitude, subjective norm and perceived control in relation to social class, income and sex, and the exceptions are discussed later.

\section{Frequency of eating and preference for selected starchy foods}

Analyses of the food-frequency question showed the mean starch intake of the total sample to be 130 (SD 3) g starch/d from the food groups included in the questionnaire. This seems to be a reasonable value, given that Gregory et al. (1990) reported an average UK adult intake of $117 \mathrm{~g} / \mathrm{d}$ nonsugar carbohydrate derived from cereal and grain products and potatoes. The mean starch intake of the respondent population was then used to classify respondents into a low reported starch intake (LRS) group ( $\leqslant 130 \mathrm{~g}$ starch/d, $n$ 224), and a high reported starch intake (HRS) group $(>130 \mathrm{~g}$ starch/d, $n$ 176), and these groups were compared for a range of other response measures.

\section{Components of the theory of planned behaviour}

Table 1 shows the contribution of the components of the TPB to the overall prediction of the dependent variables 'intention to increase starchy food intake' and 'reported starch intake'. The best fitting multiple regression model included attitude and subjective norm, and these were both significant contributors to the prediction of intention to increase starchy food intake. Perceived control did not significantly contribute to the prediction of intention to increase starchy food intake. For the overall prediction of reported starch intake, the best fitting model included attitude. However, the adjusted $r^{2}$ was not high.

Table 2 shows the results of improvement in the overall prediction of the models, after addition of the other variables 'perceived starchy food intake', 'stage of change', 'habit', 'cost' and 'family's liking of starchy foods' to the significant contributors of the first TPB model (attitude and subjective norm for intention to increase starchy food intake; and attitude for reported starch intake). The model including attitude and 'family's liking of starchy foods' had the best fit for predicting intention to increase starchy food intake, and they were both significant contributors. Addition of 'family's liking of starchy foods' to the first TPB model improved the fit. For reported starch intake, the model including attitude had the best fit, and attitude was a significant contributor. Addition of other factors to this TPB model did not improve the fit. Furthermore, the adjusted $r^{2}$ was low relative to equations predicting intention to increase starchy food intake.

In general, respondents had a weakly positive attitude towards increasing the proportion of starchy foods in their diet and felt highly in control (Table 3), and the intention to increase starchy food intake was negative. Even when respondents were classified as LRS or HRS, or by positive attitudes (attitude score +1 to +3 ) or negative attitudes (attitude score -1 to -3 ), similar results were found (results not shown).

The belief $\times$ outcome evaluation items were generally positive (Table 4). Starchy foods were viewed as good for the health, filling, easy and quick to prepare and cook, tasty and nutritious; however, respondents did not view starchy foods as helpful in weight control. The beliefs respondents

Table 2. Improvement of the overall predictiveness of the generated theory of planned behaviour models with either intention to increase starchy food intake or reported starch intake as dependent variable, by adding other factors to the model

\begin{tabular}{|c|c|c|c|c|c|c|}
\hline Step & Variables in model & Adjusted $R^{2}$ & $P$ & $\beta$ & $t$ & $P$ \\
\hline \multicolumn{7}{|c|}{ Intention to increase starchy food intake } \\
\hline 1 & + attitude & 0.21 & $<0.001$ & 0.45 & $10 \cdot 08$ & $<0.001$ \\
\hline 2 (final) & $\begin{array}{l}+ \text { attitude } \\
+ \text { family's liking of } \\
\text { starchy foods }\end{array}$ & 0.25 & $<0.001$ & $\begin{array}{l}0.42 \\
0.22\end{array}$ & $\begin{array}{l}9.49 \\
4.97\end{array}$ & $\begin{array}{l}<0.001 \\
<0.001\end{array}$ \\
\hline \multicolumn{7}{|c|}{ Reported starch intake } \\
\hline 1 (final) & + attitude & 0.01 & 0.04 & 0.11 & $2 \cdot 10$ & 0.036 \\
\hline
\end{tabular}


Table 3. Values for the 'theory of planned behaviour' components attitude, subjective norm, perceived control and intention to increase the proportion of starchy foods in the diet for the total population sample $(n 414)$ and for those with a low $(\leqslant 130 \mathrm{~g} / \mathrm{d}, n 223)$ or a high $(>130 \mathrm{~g} / \mathrm{d}$, $n$ 174) reported starch intake

(Mean values and standard deviations)

\begin{tabular}{|c|c|c|c|c|c|c|c|c|c|c|}
\hline \multirow[b]{2}{*}{ Component } & \multicolumn{2}{|c|}{ Total sample } & \multicolumn{2}{|c|}{$\begin{array}{l}\text { Statistical significance } \\
\text { of difference from } \\
\text { midpoint }\end{array}$} & \multicolumn{2}{|c|}{$\begin{array}{l}\text { Low reported } \\
\text { starch intake }\end{array}$} & \multicolumn{2}{|c|}{$\begin{array}{l}\text { High reported } \\
\text { starch intake }\end{array}$} & \multicolumn{2}{|c|}{$\begin{array}{c}\text { Statistical significance } \\
\text { of difference between } \\
\text { groups }\end{array}$} \\
\hline & Mean & SD & $t$ & $P$ & Mean & SD & Mean & SD & $t$ & $P$ \\
\hline Attitude* $^{*}$ & 0.58 & $2 \cdot 1$ & -32.5 & $<0.001$ & 0.27 & $2 \cdot 1$ & 0.93 & $2 \cdot 1$ & -3.01 & 0.002 \\
\hline Subjective norm* & -0.74 & $1 \cdot 3$ & -71.9 & $<0.001$ & -0.78 & $1 \cdot 3$ & -0.70 & 1.4 & -0.54 & 0.58 \\
\hline Perceived control† & $6 \cdot 15$ & $1 \cdot 3$ & 93.7 & $<0.001$ & $6 \cdot 15$ & $1 \cdot 3$ & $6 \cdot 17$ & $1 \cdot 3$ & -0.16 & 0.87 \\
\hline Intention* & -0.88 & 1.6 & $-63 \cdot 6$ & $<0.001$ & -0.95 & 1.6 & -0.78 & 1.5 & -1.09 & 0.27 \\
\hline
\end{tabular}

* Possible range -3 to 3 , scale midpoint 0 .

† Possible range $1-7$, scale midpoint 4.

held were related to their attitude, e.g. respondents with a positive attitude towards increasing starchy food intake thought that starchy foods were good for the health, nutritious, easy to prepare and cook, helped to control weight and were not high in energy. Respondents with a negative attitude, however, felt less convinced about the health and nutritional status of starchy foods, in particular their energy content and the role in helping to control weight. There were, however, no significant differences in belief $\times$ outcome evaluation items between respondents in the LRS or HRS groups (results not shown).

\section{Questions relating to barriers towards increasing starchy food intake}

(a) Perceived starchy food intake. In general, respondents viewed their own starchy food intake to be slightly above average in absolute terms (0.62 (SD 1.03), on a scale from -3 to $+3, t 12 \cdot 04, P<0 \cdot 001 v$. neutral midpoint). There was a significant difference between people from the LRS and HRS groups: LRS perceived their starchy food intake to be slightly high compared with HRS (0.52 (SD 1.05) v. $0.74(\mathrm{SD} \mathrm{1.03)}$ respectively, on a scale from -3 to +3 , $t-2.07, P=0.04 v$. each other; and $t 7.35, P<0.001$ and $t 9.413, P<0.001 v$. neutral midpoint respectively). There was no significant difference in perceived starchy food intake between respondents with a positive or a negative attitude.

(b) Recognition of current dietary guidelines about starchy foods. When asked to what extent people believed they should change their starchy food intake to make it more healthy, respondents overall believed they should reduce the proportion of starchy foods they have in their diet ( $-0 \cdot 19$ (SD 0.93 ) on a scale from -3 to $+3 ; t-4.195, P<0.001 v$. midpoint 0). Again, there was a significant difference between respondents with a positive or a negative attitude: respondents with a positive attitude believed they should increase their starchy food intake to make their diets more healthy $(0.15$ (SD 0.91$), t 2.22, P=0.03 v$. midpoint 0$)$, whereas those with a negative attitude believed they should reduce it $(-0.59$ (SD 0.78), $t-8.529, P<0.001 v$. midpoint 0 ; and $t-7.709, P<0.001 v$. each other). LRS and HRS groups believed they should reduce their starchy food intake slightly, the former more than the latter (-0.23 (SD 0.93)

Table 4. Mean belief $\times$ evaluation scores* for the total sample and specified for those with a positive or a negative attitude towards increasing starchy food intake

\begin{tabular}{|c|c|c|c|c|c|}
\hline \multirow[b]{2}{*}{ Belief $\times$ evaluation items } & \multirow{2}{*}{$\begin{array}{l}\text { Total sample } \\
\text { (n 414) }\end{array}$} & \multirow{2}{*}{$\begin{array}{l}\text { Positive attitude } \\
\text { (n 127) }\end{array}$} & \multirow{2}{*}{$\begin{array}{c}\text { Negative attitude } \\
(n 191)\end{array}$} & \multicolumn{2}{|c|}{$\begin{array}{c}\text { Statistical significance of } \\
\text { difference between } \\
\text { attitude groups }\end{array}$} \\
\hline & & & & $t$ & $P$ \\
\hline Are good for my health & $10 \cdot 8$ & 12.90 & 8.63 & -5.05 & $<0.001$ \\
\hline Help to control my weight & 2.5 & 5.56 & -0.81 & $-6 \cdot 72$ & $<0.001$ \\
\hline Are filling & $11 \cdot 6$ & $12 \cdot 66$ & 10.93 & $-2 \cdot 17$ & 0.031 \\
\hline Are easy to prepare and cook & $11 \cdot 6$ & 13.03 & $10 \cdot 40$ & $-3 \cdot 14$ & 0.002 \\
\hline Are easy to digest & $7 \cdot 3$ & 8.65 & $6 \cdot 15$ & -2.91 & 0.004 \\
\hline Are quick to prepare and cook & $10 \cdot 5$ & 11.98 & $9 \cdot 71$ & -2.88 & 0.004 \\
\hline Are tasty & $11 \cdot 7$ & 12.96 & $10 \cdot 33$ & $-3 \cdot 25$ & 0.001 \\
\hline Are nutritious & $10 \cdot 3$ & 12.04 & 8.64 & -4.01 & $<0.001$ \\
\hline Make my meals less expensive & $7 \cdot 8$ & $9 \cdot 21$ & $7 \cdot 25$ & $-2 \cdot 30$ & 0.022 \\
\hline Are interesting & 6.5 & 8.53 & 4.68 & -4.56 & $<0.001$ \\
\hline Are high in energy & $-2 \cdot 1$ & -0.89 & $-4 \cdot 19$ & $-4 \cdot 12$ & $<0.001$ \\
\hline My family likes & $9 \cdot 8$ & $10 \cdot 32$ & $9 \cdot 22$ & $-1 \cdot 29$ & 0.199 \\
\hline Are easy to store & $9 \cdot 7$ & $10 \cdot 78$ & $8 \cdot 71$ & -2.58 & $<0.010$ \\
\hline
\end{tabular}

*Possible range from -21 to 21. 
v. -0.12 (SD 0.93) respectively, on a scale from -3 to +3 ; $t-3.792, P<0.001$ and $t-1.796, P=0.07$ respectively $v$. neutral midpoint; and $t-1 \cdot 183, P=0.24 v$. each other).

(c) Stage of change in relation to starchy food intake. When respondents were asked if they had ever thought about changing their starchy food intake, about a fifth of them answered that they had never thought about changing their starchy food intake or that they did not need to change it. About $16 \%$ of the respondents indicated that they had increased the proportion of starchy foods in their diet, and $3.7 \%$ indicated they had tried (but failed) to increase it (results not shown). Again, those with positive attitudes indicated that they had already increased their starchy food intake, whereas those with a negative attitude indicated they had decreased their starchy food intake, or thought they did not need to change it (results not shown).

(d) Specific barriers towards increasing starchy food intake. Although cost did not significantly contribute to the prediction of intention to increase starchy food intake, both cost and family's liking of starchy foods were perceived as being specific barriers to the intention to increase starchy food intake (-1.08 (SD 1.46) and -0.64 (SD 1.43) respectively; $t-15 \cdot 0, P<0.001$, and $t-9 \cdot 109, P<0.001 v$. neutral midpoint 0$)$. Habit, however, was not perceived as a barrier at all $(-0.52($ SD 1.77$), t-5.912, P<0.001 v$. neutral midpoint 0 ). Cost and family's liking of starchy foods were perceived more significantly to be barriers by people with a negative attitude compared with those with a positive attitude (results not shown).

\section{Discussion}

To our knowledge, this is the first survey which has directly focused on UK consumer attitudes and beliefs relating specifically to consumption of starchy food sources of complex carbohydrate. The results point to a number of issues where consumers might benefit from further information or guidance, and which could be a useful focus for health promotion efforts.

In general, this analysis of a UK consumer population revealed divergent attitudes towards starchy foods and dietary guidance to increase intakes of these foods. The mean attitude was slightly positive; however, this reflected clear recognition of benefits from starchy food consumption amongst a group with positive attitudes. A somewhat larger group with generally negative attitudes towards these foods differed from respondents with more positive attitudes in the strength of their beliefs that starchy foods are 'high in energy' and 'do not help to control weight' and a clear corresponding intention not to increase intakes.

It is apparent from other research that many consumers are capable of distinguishing between starchy foods which have lower or higher fat contents, and characterize the latter (e.g. roast and chipped potatoes, crisps) as 'fattening' (Monteleone et al. 1997, 1998). Nevertheless, the present results show that there are many consumers whose negative attitudes towards starchy foods in general are particularly characterized by the beliefs that starchy foods are high in energy and do not help to control weight. This suggests that strategies to increase starchy food intake should perhaps focus on the low energy density of many starchy food items, and explain that the 'fattening' perception may relate more closely to sauces, spreads and toppings which might be used in conjunction with bread, rice, potatoes or pasta, rather than to these foods themselves. Greater provision of alternatives to traditional preparation practices might also be helpful. In addition, it may be useful to take advantage of the generally accepted positive views of the nutritional role of starchy foods in supplying essential nutrients and providing good value for money (filling).

\section{Components of the theory of planned behaviour}

Using the structured model and analyses of Ajzen \& Fishbein (1980) and Ajzen (1985), we found that intention to increase starchy food intake was best predicted by the model including attitude and subjective norm, and both variables proved to be significant predictors. However, although the attitude component had the greatest predictive power, the relationship was weak. In addition, the relationships amongst the components of the TPB and intention were not strong. This could be due to an actual weak relationship between attitude and intention to increase starchy food intake, or could be due to 'attitude variability' (Sparks et al. 1992): people may have favourable attitudes towards a particular food because of its sensory qualities, but at the same time have unfavourable attitudes to the perceived health risks involved with that food. In many other studies using the TPB to predict dietary behaviours, attitude was also reported as the most important predictor of intention; e.g. for reducing dietary intake of fat and sugar (Saunders \& Rahilly, 1990) and consuming different types of milk (Raats, 1992).

Perceived control did not contribute to the prediction of intention to increase the proportion of starchy foods in the diet. This might be attributed to different causes. One explanation could be the volitional character of the behaviour. Perceived control has been shown to be important where the dependent variable is clearly not a volitional behaviour (Ajzen, 1985). Since the behaviour in the present study was entirely volitional, inclusion of perceived control in the model did not increase the prediction of intention to increase starchy food intake. Another explanation could be the general way in which the perceived control question was asked. According to Bandura (1986) and Sparks et al. (1992), different sorts of control problems exist for different sorts of behaviour. To ensure a greater association between perceived control and behaviour, the perceived control question should be asked in different ways.

Reported starch intake was best predicted by the model including attitude, and attitude was a significant contributor. However, the relationship was very weak. This might be due to our crude measure of reported starch intake, which provided only a rough estimation of starch intake. However, other attitudinal studies which measured dietary behaviour precisely using the weighed intake method found no association between fat intake and 'fat phobic' attitudes in men, and only weak associations in women (Barker et al. 1995). Therefore, it could be that the actual relationship between attitude and reported starch intake is weak.

Addition of other factors such as perceived starchy food intake, stage of change, habit, cost and family's liking of starchy foods, improved predictive equations for intention 
to increase starchy food intake, but not for reported starch intake. Addition of 'family's liking of starchy foods' after 'attitude' significantly improved the prediction of intention to increase starchy food intake. This is in keeping with the studies of Povey et al. (1994), Paisley (1994) and Sparks et al. (1992), in which family pressures to remain with familiar eating practices were the main barriers towards changing to a healthier diet. Perceived starchy food intake, stage of change and habit did not have significant influence at all. This is in contradiction with the findings of Shepherd (1992), Shepherd \& Sparks (1994), and Brug \& van Assema (1995), who have shown that habit is a key factor in the maintenance of frequently repeated behaviour.

\section{Questions relating to barriers towards increasing starchy food intake}

(a) Perceived starchy food intake. The people who perceived their starchy food intake to be high had a more positive attitude towards increasing starchy food intake than those with a low perceived starchy food intake. This is consistent with studies of other foods; for example, Brug et al. (1995) found that respondents reporting low consumption of fruit and vegetables had a less positive attitude towards increasing fruit and vegetable intake than respondents reporting relatively high intakes.

(b) Recognition of current dietary guidelines about starchy foods. The present survey has indicated a poor general awareness that increasing starchy food intake is part of current general dietary guidance. Respondents with a positive attitude tended to recognize this guidance, whereas those with a negative attitude did not, and actually thought they should be reducing starchy food intakes. This low awareness of starchy food consumption as a dietary recommendation is consistent with results from Lloyd et al. (1993) and Goode et al. (1995). There is still a need for health promotion messages which might be directed at improving understanding of starchy foods and their role in a healthy diet.

(c) Stage of change in relation to starchy food intake. Stage of change was very much related to individuals' attitude and beliefs, and their perception of their starchy food intake. Those individuals who had a negative attitude and reported a low intake indicated that they had already reduced their intake or were planning to reduce it, whereas those with a positive attitude who reported a high intake had already increased their intake or were planning to increase it. This was also reported by Glanz et al. (1994) and Brug et al. (1994).

The convenience sample we used was highly skewed towards higher income classes, and not stratified. This may have influenced our outcomes considerably, and our results may differ from those for a more stratified sample. Given that there was a high degree of uncertainty of current dietary guidance, and divergent views about the benefits of high consumption of these foods, it is possible that the process of completing a questionnaire that specifically asked about increasing starchy food intake may have raised respondents' awareness of the issue and prompted the expression of more socially 'desirable' responses.

\section{Conclusions}

A structured questionnaire based on the TPB (Ajzen, 1985) indicated that the model including attitude and subjective norm was the best fit for the prediction of reported intention to increase starchy food consumption, and that attitude was the strongest contributor. Addition of the factor 'family's liking of starchy foods' significantly improved the model. For reported starch intake, the model including attitude had the best fit, and addition of other factors did not improve the model.

In general, UK consumers hold divergent attitudes towards increasing the proportion of starchy foods in the diet. Interventions to increase starchy food consumption should therefore include strategies aimed at converting people from a negative attitude to a positive attitude, particularly by addressing the beliefs that starchy foods are high in energy and do not help in weight control, and emphasizing the nutritional value of these foods. Also, the low recognition of current dietary guidance in relation to starchy food consumption should be considered in the development of health promotion messages.

\section{Acknowledgements}

The authors would like to thank Drs Monique Raats and Erminio Monteleone for their helpful contributions to the design of the survey. This work was funded by a Competitive Strategic Grant from the Biotechnology \& Biological Sciences Research Council and was carried out in 1995 by Karin Stubenitsky in partial fulfilment of a MSc in Health Sciences at the University of Maastricht, under the supervision of Dr Margriet Westerterp-Plantenga.

\section{References}

Ajzen I (1985) From intentions to action: a theory of planned behaviour. In Action Control: From Cognition to Behaviour, pp. 11-39 [J Kuhl \& J Beckman, editors]. Heidelberg: Springer.

Ajzen I \& Fishbein M (1980) Understanding Attitudes and Predicting Social Behaviour. Englewood Cliffs, NJ: Prentice Hall.

Bandura A (1986) Social Foundations of Thought and Action. A Social Cognitive Theory. Englewood Cliffs, NJ: Prentice Hall.

Barker ME, Thompson KA \& McClean SI (1995) Attitudinal dimensions of food choice and nutrient intake. British Journal of Nutrition 74, 649-659.

Brug J, Lechner L \& de Vries H (1995) Psychosocial determinants of fruit and vegetable consumption. Appetite 25, 285-296.

Brug J \& van Assema P (1995) Factors differentiating between stages of change for fat consumption reduction. Appetite $\mathbf{2 4}$, 296.

Brug J, van Assema P, Kok G, Lenderink T \& Glanz K (1994) Selfrated dietary fat intake: association with objective assessment of fat, psychosocial factors and intention to change. Journal of Nutrition Education 26, 218-223.

Buttriss JL (1997) Food and nutrition: attitudes, beliefs and knowledge in the United Kingdom. American Journal of Clinical Nutrition 65, 1985s-1995s.

Cannon G (1992) Food and Health: The Experts Agree. London: Consumers' Association.

Department of Health (1994) Nutritional Aspects of Cardiovascular Disease. Report on Health and Social Subjects no. 46. London: H.M. Stationery Office. 
Dickinson JR \& Faria AJ (1995) Refinements of charitable contribution incentives for mail surveys. Journal of the Market Research Society 37, 447-453.

Glanz K, Patterson RE, Kristal AR, DiClemente CC, Heimendinger J, Linnan L \& McLerran DF (1994) Stages of change in adopting healthy diets: fat, fibre and correlates of nutrient intake. Health Education Quarterly 21, 499-519.

Goode J, Beardsworth A, Haslam C, Keil T \& Sherratt E (1995) Dietary dilemmas: Nutritional concerns of the 1990s. British Food Journal 97, 3-12.

Gregory J, Foster K, Tyler H \& Wiseman M (1990) The Dietary and Nutritional Survey of British Adults. London: H.M. Stationery Office.

Lloyd HM, Paisley CM \& Mela DJ (1993) Changing to a low-fat diet: attitudes and beliefs of UK consumers. European Journal of Clinical Nutrition 47, 361-373.

Lloyd HM, Paisley CM \& Mela DJ (1995) Barriers to the adoption and maintenance of reduced fat diets. Journal of the American Dietetic Association 95, 316-322.

Meiselman HL (1994) A measurement scheme for developing institutional products. Chapter 1. In Measurement of Food Preferences, pp. 1-24 [HJH MacFie and DMH Thomson, editors]. London: Chapman \& Hall.

Ministry of Agriculture, Fisheries and Food (1992) National Food Survey 1991. Annual Report on Household Food Consumption and Expenditure. London: H.M. Stationery Office.

Ministry of Agriculture, Fisheries and Food (1993) Food Portion Sizes. London: H.M. Stationery Office.

Ministry of Agriculture, Fisheries and Food (1996) National Food Survey 1995. Annual Report on Household Food Consumption and Expenditure. London: H.M. Stationery Office.

Monteleone E, Frewer L, Wakeling I \& Mela DJ (1998) Individual differences in starchy food consumption: the application of preference mapping. Food Quality and Preference 9, 211-219.

Monteleone E, Raats MM \& Mela DJ (1997) Perceptions of starchy food dishes: application of the Repertory Grid Method. Appetite 28, 255-265.

Office of Population Censuses and Surveys (1991) Classification of Occupations. London: H.M. Stationery Office.

Paisley CM (1994) Barriers to the adoption and maintenance of reduced fat diets. PhD Thesis, University of Reading.
Paisley CM, Lloyd HM \& Mela DJ (1995a) Perceptions of dietary changes aimed at reducing fat intake among UK consumers. Appetite 24, 242-245.

Paisley CM, Lloyd HM, Sparks P \& Mela DJ (1995b) Consumer perceptions of dietary changes for reducing fat intake. Nutrition Research 15, 1755-1766.

Paul AA \& Southgate DAT (1978) McCance and Widdowson's The Composition of Foods, 4th ed. London: H.M. Stationery Office.

Povey R, Conner M, James R, Sparks P \& Shepherd R (1994) Lay interpretations of healthy eating. Appetite 24, 284.

Prochaska JO (1992) In search of how people change: applications to addictive behaviours. American Psychologist 9, 11021114.

Raats MM (1992) The role of beliefs and sensory responses to milk in determining the selection of milks of different fat content. $\mathrm{PhD}$ Thesis, University of Reading.

Saunders RP \& Rahilly SA (1990) Influences on intention to reduce dietary intake of fat and sugar. Journal of Nutrition Education 22, 169-176.

Shepherd R (1992) Nutritional and sensory beliefs in food choice. British Food Journal 92, 3-8.

Shepherd R, Paisley CM, Eley S, Sparks P, Anderson AS \& Lean MEJ (1997) Healthier eating: income, difficulty and food intake. Proceedings of the Nutrition Society 56, 59A Abstr.

Shepherd R \& Sparks P (1994) Modelling food choice. In Measurement of Food Preferences, pp. 203-224 [HJH MacFie and DMH Thompson, editors]. Glasgow: Chapman \& Hall.

Sparks P, Hedderley D \& Shepherd R (1992) An investigation into the relationship between perceived control, attitude variability and the consumption of two common foods. European Journal of Social Psychology 22, 555-571.

Stephen MS, Sieber GM, Gerster YA \& Morgan DR (1995) Intake of carbohydrate and its components - international comparisons, trends over time, and effects of changing to low-fat diets. American Journal of Clinical Nutrition 62, 851s-867s.

Towler G \& Shepherd R (1991) Application of Fishbein and Ajzen's expectancy-value model to understanding fat intake. Appetite 18, 15-27. 